\title{
Treatment of stage I lung cancer in high-risk and inoperable patients: Comparison of prospective clinical trials using stereotactic body radiotherapy (RTOG 0236), sublobar resection (ACOSOG Z4032), and radiofrequency ablation (ACOSOG Z4033)
}

Traves Crabtree, MD, ${ }^{\mathrm{a}}$ Varun Puri, MD, ${ }^{\mathrm{a}}$ Robert Timmerman, MD, ${ }^{\mathrm{b}}$ Hiran Fernando, MD, ${ }^{\mathrm{c}}$ Jeffrey Bradley, MD, ${ }^{\mathrm{d}}$ Paul A. Decker, MS, ${ }^{\mathrm{e}}$ Rebecca Paulus, PhD,${ }^{\mathrm{f}}$ Joe B. Putnum, Jr, MD, ${ }^{\mathrm{g}}$ Damian E. Dupuy, MD, ${ }^{\mathrm{h}}$ and Bryan Meyers, MD, $\mathrm{MPH}^{\mathrm{a}}$

Objective: The purpose of the present study was to compare the selection criteria and short-term outcomes among 3 prospective clinical trials using stereotactic body radiotherapy (Radiation Therapy Oncology Group [RTOG] trial 0236), sublobar resection (American College of Surgeons Oncology Group [ACOSOG] trial Z4032), and radiofrequency ablation (ACOSOG trial Z4033).

Methods: The selection criteria and outcomes were compared among RTOG $0236(n=55)$, ACOSOG Z4032 $(\mathrm{n}=211)$, and ACOSOG Z4033 ( $\mathrm{n}=51)$. Age, Eastern Cooperative Oncology Group performance status, percentage of predicted forced expiratory volume in 1 second, and percentage of predicted carbon monoxide diffusing capacity of the lung were used to perform a propensity-matched analysis among patients with clinical stage 1A in RTOG 0236 and ACOSOG Z4032.

Results: The patients in ACOSOG Z4033 undergoing radiofrequency ablation were older (75.6 \pm 7.5 years) than those in RTOG 0236 (72.5 \pm 8.8 years) and ACOSOG Z4032 (70.2 \pm 8.5 years; $P=.0003)$. The pretreatment percentage of predicted forced expiratory volume in 1 second was $61.3 \% \pm 33.4 \%$ for RTOG $0236,53.8 \% \pm 19.6 \%$ for ACOSOG Z4032, and $48.8 \% \pm 20.3 \%$ for ACOSOG Z4033 $(P=.15)$. The pretreatment percentage of predicted carbon monoxide diffusing capacity of the lung was $61.6 \% \pm 30.2 \%$ for RTOG $0236,46.4 \% \pm 15.6 \%$ for ACOSOG Z4032, and 43.7\% $\pm 18.0 \%$ for ACOSOG Z4033 $(P=.001)$. The overall 90 -day mortality for stereotactic body radiotherapy, surgery, and radiofrequency ablation was $0 \%, 2.4 \%(5 / 211)$, and $2.0 \%(1 / 51)$, respectively $(P=.5)$. Overall, the unadjusted 30-day grade $3+$ adverse events were more common with surgery than with stereotactic body radiotherapy ( $28 \%$ vs $9.1 \%, P=.004)$, although no difference was between the 2 groups at 90 days. Among the patients with clinical stage IA in ACOSOG Z4032, 29.3\% had a more advanced pathologic stage at surgery. A propensity-matched comparison showed no difference between stereotactic body radiotherapy and surgery for 30-day grade $3+$ adverse events (odds ratio, 2.37; 95\% confidence interval, $0.75-9.90 ; P=.18$ ).

Conclusions: Among appropriately matched patients, no difference was seen in early morbidity between sublobar resection and stereotactic body radiotherapy. These results underscore the need for a randomized trial to delineate the relative survival benefit of each modality and to help stratify patients considered high risk. (J Thorac Cardiovasc Surg 2013;145:692-99)

\footnotetext{
From the Division of Thoracic Surgery ${ }^{\mathrm{a}}$ and Department of Radiation Oncology, ${ }^{\mathrm{d}}$ Washington University School of Medicine, St. Louis, Mo; Department of Radiation Oncology, ${ }^{\mathrm{b}}$ University of Texas Southwestern Medical School, Dallas, Tex; Division of Thoracic Surgery, ${ }^{\mathrm{c}}$ Boston University Medical Center, Boston, Mass; Division of Biomedical Statistics and Informatics, ${ }^{\mathrm{e}}$ Mayo Clinic, Rochester, Minn; Radiation Therapy Oncology Group Statistical Center, ${ }^{\mathrm{f}}$ Philadelphia, Pa; Department of Thoracic Surgery, ${ }^{\mathrm{g}}$ Vanderbilt University, Nashville, Tenn; and Department of Radiology, ${ }^{\mathrm{h}}$ Brown University School of Medicine, Providence, RI. Disclosures: Authors have nothing to disclose with regard to commercial support. Read at the 38th Annual Meeting of The Western Thoracic Surgical Association, Maui, Hawaii, June 27-30, 2012.

Received for publication June 14, 2012; revisions received Sept 7, 2012; accepted for publication Oct 22, 2012; available ahead of print Nov 21, 2012

Address for reprints: Traves Crabtree, MD, Division of Thoracic Surgery, Washington University School of Medicine, 3108 Queeny Tower, 1 Barnes Hospital Plaza, St. Louis, MO 63110 (E-mail: crabtreet@wustl.edu).

0022-5223/ $\$ 36.00$

Copyright (c) 2013 by The American Association for Thoracic Surgery

http://dx.doi.org/10.1016/j.jtcvs.2012.10.038
}

The reference standard for treatment of stage I non-small cell lung cancer (NSCLC) in operable patients is surgical resection with lobectomy and systematic lymph node evaluation. However, a significant number of patients with stage I lung cancer are considered medically inoperable or highrisk surgical candidates. ${ }^{1,2}$ In an aging population, pulmonary insufficiency and cardiac comorbidities could preclude surgery or place patients at significant risk of complications after surgery. Although surgery has been the mainstay of therapy for high-risk patients, the evolution of nonsurgical therapies, such as stereotactic body radiotherapy (SBRT) and radiofrequency ablation (RFA), have raised the issues of patient selection, treatment-related morbidity, and the relative oncologic efficacy of each therapy.

Before the development of SBRT and RFA, patients considered at high risk or unsuitable for lobectomy were 


\section{Abbreviations and Acronyms \\ ACOSOG $=$ American College of Surgeons Oncology Group \\ AEs = adverse events \\ $\mathrm{DLCO} \%=$ percentage of predicted carbon monoxide diffusing capacity of the lung \\ $\mathrm{FEV}_{1} \%=$ percentage of predicted forced expiratory volume in 1 second \\ NSCLC $=$ non-small cell lung cancer \\ PFT = pulmonary function test \\ RFA $=$ radiofrequency ablation \\ RTOG = Radiation Therapy Oncology Group \\ SBRT = stereotactic body radiotherapy}

generally offered surgery with sublobar resection. In these patients with marginal lung function, sublobar resection is potentially advantageous because of the preservation of lung function. ${ }^{3,4}$ Single-center studies have shown a decrease in local recurrence rates for patients undergoing sublobar resection with the addition of brachytherapy compared with sublobar resection alone (17.2\%-18.6\% vs $2 \%-3.3 \%)^{5,6}$ Because of these data, a phase III randomized controlled trial (American College of Surgeons Oncology Group [ACOSOG] trail Z4032) was developed that randomized patients with stage I NSCLC to either sublobar resection or sublobar resection with brachytherapy. ${ }^{7}$ The local recurrence data and diseaserelated survival should become available within 1 to 2 years.

RFA and SBRT have been used with increasing frequency in the medically inoperable and high-risk population with early-stage NSCLC. In small series of patients undergoing RFA, the 2-year survival has ranged from $57 \%$ to $78 \%$ among patients with early-stage NSCLC. ${ }^{8-11}$ A phase II prospective nonrandomized trial examining high-risk patients with stage I NSCLC using RFA (ACOSOG Z4033) has completed accrual, but the survival and recurrence data have not yet matured.

In contrast to conventional fractionated radiotherapy, SBRT provides a high dose per fraction to the tumor distributed within a few fractions, ${ }^{3-5}$ creating an ablative mechanism for tumor destruction, while the steep dose gradients help to avoid damage to the surrounding parenchyma and other structures. Studies of SBRT in medically inoperable and some operable patients with early-stage NSCLC have reported relatively low local recurrence rates, ranging from $3 \%$ to $20 \%$, depending on the delivered biologic effective dose, length of follow-up, and definition of local failure. ${ }^{12-21}$ Given the comorbidity in this population, overall survival is often expectedly modest, ranging from $32 \%$ to $57 \%$ at 3 years in single-center studies. A subsequent phase II North American trial of SBRT
(Radiation Therapy Oncology Group [RTOG] 0236) revealed a 3-year disease-free and overall survival of $48 \%$ and $56 \%$, respectively, in patients with stage I NSCLC who had been deemed inoperable by a surgeon or pulmonologist. ${ }^{22}$ These data prompted the comparative study of SBRT and surgery in high-risk operable patients with early-stage NSCLC (ACOSOG Z4099/RTOG 1021). The latter trial only recently opened and results are years away. As we begin to integrate this new technology into the treatment of NSCLC, it will be important for us to have a clear understanding of the selection criteria, relative treatmentrelated morbidity and mortality, and oncologic efficacy.

The present retrospective study was designed to compare the entrance criteria, short-term outcomes, and early changes in pulmonary function tests (PFTs) among 3 clinical trials using sublobar resection (ACOSOG Z4032), SBRT (RTOG 0236), and RFA (ACOSOG Z4033) in the highrisk and inoperable patient population with early-stage NSCLC. A comparison of the entrance criteria among these studies was performed to show a spectrum of comorbidity across each study and to identify potential overlap among the studies. Propensity matching was used to compare the short-term outcomes, morbidity, and mortality. Understanding the current selection criteria and relative comorbidities in each cohort could help us to establish an objective risk stratification system in the future to guide us in selection of therapy for this challenging patient population.

\section{METHODS}

The present study was a retrospective secondary analysis of prospectively collected data from 3 multicenter clinical trials. The data were formally requested from the RTOG and ACOSOG, and the analysis was approved by both organizations. The institutional review board at Washington University School of Medicine also approved the present study. From these data, we compared the pretreatment (baseline) characteristics, including demographic data, pulmonary function, and other comorbidities, when available. PFTs included the percentage of predicted forced expiratory volume in 1 second $\left(\mathrm{FEV}_{1} \%\right)$ and percentage of predicted carbon monoxide diffusing capacity of the lung (DLCO \%) measured preoperatively and 90 days after treatment completion. The disease of all patients was clinically staged using chest computed tomography (CT) and fluorodeoxyglucosepositron emission tomography.

RTOG 0236 was a phase II, multicenter, North American trial examining the efficacy of SBRT in patients with stage I NSCLC who were considered medically inoperable. The study, opened in 2004 , enrolled 59 patients to complete accrual, and midterm survival data have been published for 55 evaluable patients. ${ }^{22}$ The primary endpoint was local control, with secondary endpoints of treatment-related toxicity, disease-free survival, overall survival, and patterns of failure. The patients received 3 fractions of $20 \mathrm{~Gy}$ each within 8 to 14 days. The patients were considered inoperable based on the evaluation findings from a thoracic surgeon or pulmonologist (Table 1). The prospectively collected PFT data were incomplete and were supplemented post hoc after a retrospective chart review. All data regarding pretreatment comorbidity provided by the RTOG were included in the synopsis of the results.

ACOSOG Z4032 was a randomized phase III trial comparing sublobar resection and sublobar resection plus brachytherapy in patients with stage I NSCLC who were considered too high risk for surgery. The study was closed to accrual in January 2010 after a planned enrollment of 222 evaluable patients. The primary outcome measure was the interval to local 
TABLE 1. Criteria for medically inoperable or high-risk surgical patients from recent clinical trials of surgery or radiotherapy

Criteria for medically inoperable patients undergoing SBRT (RTOG 0236)

Required

Patient deemed medically inoperable by an experienced thoracic cancer clinician (thoracic surgeon or pulmonologist)

Suggested criteria for medical inoperability

$\mathrm{FEV}_{1}<40 \%$ predicted

Postoperative $\mathrm{FEV}_{1}<30 \%$ predicted

Severely reduced DLCO

Hypoxemia

Hypercapnia

$\mathrm{VO}_{2}<50 \%$ predicted

Severe pulmonary hypertension

Diabetes mellitus with severe end organ damage

Severe cerebral, cardiac, or peripheral vascular disease

Severe chronic heart disease

Criteria for high-risk surgical patient undergoing sublobar resection (ACOSOG Z4032) or RFA (ACOSOG Z4033)

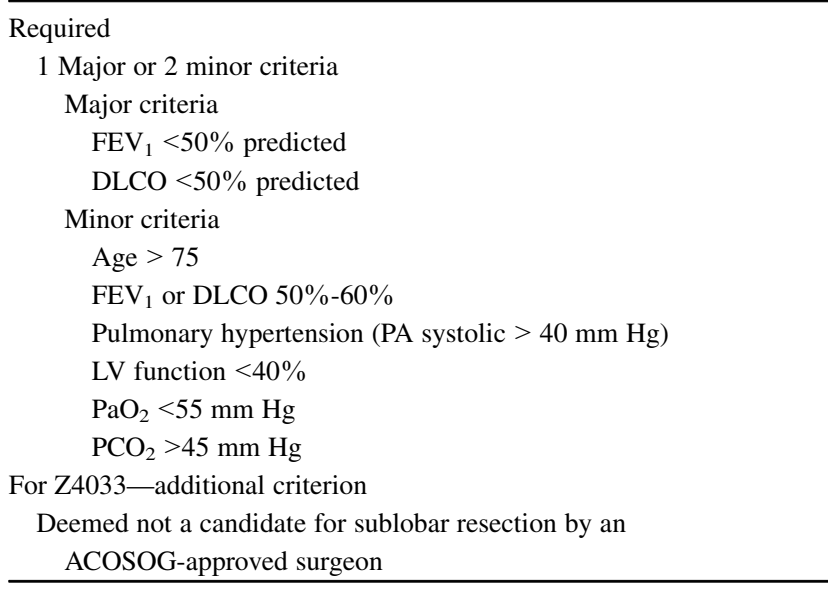

$S B R T$, Stereotactic body radiotherapy; RTOG, Radiation Therapy Oncology Group; $F E V_{l}$, forced expiratory volume in 1 second; $D L C O$, carbon monoxide diffusing capacity of lung; $\mathrm{VO}_{2}$, peak oxygen uptake; ASOSOG, American College of Surgeons Oncology Group; $R F A$, radiofrequency ablation; $P A$, pulmonary artery; $L V$, left ventricular; $\mathrm{PaO}_{2}$, partial pressure of arterial oxygen; $\mathrm{PCO}_{2}$, partial pressure of carbon dioxide.

recurrence. The secondary outcome measures included morbidity, overall and failure-free survival, regional or distant recurrence, quality of life, and pulmonary function. The initial results with early treatment-related morbidity and mortality have been published, but the primary endpoints have not yet matured. Because the primary endpoint has not yet been published, for the purposes of the present study, the surgical patients were considered 2 as 1 cohort without stratifying according to the use of brachytherapy. Based on predefined entrance criteria for this retrospective study of patients with clinical T1-2N0 disease, 1 patient from the ACOSOG Z4032 trial was ineligible for this comparison. In the previously published results of short-term outcomes from Z4032, all registered patients were included regardless of eligibility as long as they had received sublobar resection or sublobar resection plus brachytherapy in an intent-to-treat analysis. ${ }^{7}$ This excluded patient was classified in the database as clinical N2 and thus did not meet the critieria for entrance into our retrospective comparison of the 3 treatment modalities. The comorbidity and PFT data were collected prospectively, and predefined objective entrance criteria were used to define the high-risk patient (Table 1). Adverse events (AEs) were recorded using the Common Terminology Criteria for Adverse Events, version 3.0. ${ }^{23}$
Within each category of AEs, a description of severity or grade is included. Grade 1 is mild, grade 2, moderate, grade 3, severe, grade 4, lifethreatening or disabling, and grade 5 , death related to the AE.

The primary objective for ACOSOG Z4033 was the 2-year survival in high-risk patients with stage IA NSCLC undergoing RFA. Additional outcome measures included local, regional, and distant recurrence and procedure-related morbidity and mortality after RFA. The study completed accrual of 54 patients in July 2010 . The primary endpoint data are still maturing and have not yet been published. Additionally, information on AEs has not yet been published. The entry criteria for Z4033 were identical to those of Z4032, with the additional criterion that patients should be evaluated by an ACOSOG-approved surgeon and deemed not a candidate for sublobar resection. The eligibility criteria are also outlined in Table 1.

The initial comparisons of the entry criteria and short-term outcomes were performed with the raw data from all 3 clinical trials. Categorical data were compared using the chi-square test and continuous data using the Kruskal-Wallis test. Data are reported as the mean \pm standard deviation, unless otherwise stated.

Subsequent comparisons were performed specifically between RTOG 0236 and ACOSOG Z4032 for patients with clinical stage T1 tumors. Because of the ongoing randomized trial comparing SBRT and sublobar resection (ACOSOG Z4099/RTOG 1021), this additional matched comparison focused on the SBRT and sublobar resection patients, excluding the RFA patients from the subgroup analysis. Once the primary endpoints for Z4033 have been published and the long-term outcomes are available for all 3 studies, a comparative analysis of all 3 modalities will be performed. A propensity score was built for patients with clinical stage T1 tumors using age, performance score, FEV $1 \%$, and DLCO $\%$. The propensity scores were developed to estimate the adjusted risks of short-term outcomes associated with the choice of treatment (SBRT or surgery). Logistic regression analysis was used to estimate the probability of trial choice, given the listed risk factors. Patients were classified into 5 equal-size propensity score groups among the patients with complete data (groups 1-5). This analysis included 32 patients from RTOG 0236 and 202 patients from ACOSOG Z4032. Conditional logistic regression analysis with 5 strata for categorical variables and repeated measures analysis of variance with the strata as a repeated factor for continuous outcomes was used to compare the outcomes between the 2 studies. In all cases, the $P$ values were 2 -sided.

\section{RESULTS}

There were 55 evaluable patients in the RTOG 0236 study (SBRT), 211 in the ACOSOG Z4032 study (sublobar resection), and 51 in the ACOSOG Z4033 study (RFA). The basic demographics and tumor characteristics are listed in Table 2. The RFA patients were older than the SBRT and sublobar resection patients. The SBRT patients had superior $\mathrm{DLCO} \%$ than the sublobar resection and RFA patients. The patients had clinical stage $\mathrm{T} 1$ or $\mathrm{T} 2$ disease in all 3 studies. The tumor size from CT was not available for RTOG 0236 but was similar between Z4032 and Z4033 $(P=.7)$. Of the T2 tumors, $11(20 \%)$ were in the SBRT study, $3(1.4 \%)$ in the sublobar resection study, and none in the RFA study. All patients had clinical stage N0 and M0 according to the CT and positron emission tomography findings.

The SBRT patients received a total dose of $60 \pm 0.2 \mathrm{~Gy}$ (range, 58.2-60 Gy). The mean length of treatment for the SBRT patients was $8.1 \pm 2.9$ days (range, $4-24$ days). The operative time for the sublobar resection patients was $2.2 \pm 1.0$ hours, and the hospital length of stay was $6.5 \pm 5.8$ days (range, $0-41$ days). No pathologic staging 
TABLE 2. Pretreatment demographics and comorbidity profiles for RTOG 0236, ACOSOG Z4032, and ACOSOG Z4033

\begin{tabular}{|c|c|c|c|c|}
\hline Pretreatment characteristics & RTOG 0236 (SBRT) & ACOSOG Z4032 (sublobar resection) & ACOSOG Z4033 (RFA) & $P$ value \\
\hline Patients (n) & 55 & 211 & 51 & \\
\hline Mean age $(y)$ & $72.5 \pm 8.8$ & $70.2 \pm 8.5$ & $75.6 \pm 7.5$ & $.0003 *$ \\
\hline Age $>75 y$ & $21(38.9)$ & $79(37.4)$ & $30(58.8)$ & $.02 \dagger$ \\
\hline Women (n) & $34(61.8)$ & $117(55.5)$ & $28(54.9)$ & .7 \\
\hline ECOG $1-2$ & $43(78.1)$ & $169(80.1)$ & $42(82.4)$ & .86 \\
\hline Race (white) & $51(92.7)$ & $199(94.3)$ & $44(86.3)$ & $.02 \ddagger$ \\
\hline Clinical stage $1 \mathrm{~A}$ & $44(80)$ & $208(98.6)$ & $51(100)$ & $<.0001 \S$ \\
\hline Pulmonary hypertension & NR & $5(2.4)$ & $1(2.0)$ & .86 \\
\hline Poor LV function & NR & $12(5.7)$ & $6(11.8)$ & .12 \\
\hline MMRC dyspnea score & NR & $46(21.8)$ & $12(23.5)$ & .79 \\
\hline $\mathrm{pO}_{2} \leq 55 \mathrm{~mm} \mathrm{Hg}$ or $\mathrm{SpO}_{2} \leq 88 \%$ & $2(3.7)$ & $10(4.7)$ & $1(2.0)$ & .66 \\
\hline $\mathrm{pCO}_{2}>45 \mathrm{~mm} \mathrm{Hg}$ & $8(14.8)$ & $6(2.8)$ & 0 & .00029 \\
\hline $\mathrm{DLCO} \%$ & $61.6 \pm 30.2$ & $46.4 \pm 15.6$ & $43.7 \pm 18.0$ & $.001 \|$ \\
\hline $\mathrm{FEV}_{1} \%$ & $61.3 \pm 33.4$ & $53.8 \pm 19.6$ & $48.8 \pm 20.3$ & .15 \\
\hline $\mathrm{FVC} \%$ & $79.8 \pm 23.2$ & $74.8 \pm 17$ & NR & .4 \\
\hline
\end{tabular}

Data presented as mean $\pm \mathrm{SD}$ or n (\%). P values from chi-square or Kruskal-Wallis test. RTOG, Radiation Therapy Oncology Group; ACOSOG, American College of Surgeons Oncology Group; $R F A$, radiofrequency ablation; $E C O G$, Eastern Cooperative Oncology Group; $N R$, not reported; $L V$, left ventricular; $M M R C$, Modified Medical Research Council; $\mathrm{pO}_{2}$, partial pressure of oxygen; $\mathrm{SpO}_{2}$, saturation of peripheral oxygen; $\mathrm{pCO}_{2}$, partial pressure of carbon dioxide; $\mathrm{DLCO} \%$, percentage of predicted carbon monoxide diffusing capacity of lung; $F E V_{1} \%$, percentage of predicted forced expiratory volume in 1 second; $F V C \%$, percentage of forced vital capacity; $S B R T$, stereotactic body radiotherapy. $* P<.0001, \mathrm{Z} 4032$ vs Z4033. $\dagger P=.04$, RTOG 0236 vs Z4033; $P=.005$, Z4032 vs Z4033. $\ddagger P=.04$, RTOG 0236 vs Z4032. $§ P<.0001 \mathrm{RTOG}$ vs Z4032; $P=.0007$, RTOG 0236 vs Z4033. $₫ P=.0004$, RTOG 0236 vs Z4032; $P=.004$, RTOG 0236 vs Z4033. $\| P=.0008$ RTOG 0236 vs Z4032; $P=.001$, RTOG 0236 vs Z4033.

was done for the SBRT or RFA study patients. The final pathologic stage for all patients undergoing sublobar resection was pIA in $70.1 \%$, pIB in $25 \%$, IIA in $0.5 \%$, IIB in $1.6 \%$, IIIA in $1.1 \%$, IIIB in $0.5 \%$, and IV in $1.1 \%$. A total of 27 patients $(12.8 \%)$ had no documented nodal pathologic assessment after surgery. This included 14 with T1NxM0, 6 with T2NxM0, 1 with T3NxM0, and 6 with missing T, N, or M stage data.

The 30- and 90-day mortality and morbidity, including the AE data, for each study are listed in Table 3. For the RFA study, information on mortality only was available. In the RFA cohort, 1 treatment-related death occurred. The patient

TABLE 3. Comparison of mortality and post-treatment adverse events

\begin{tabular}{|c|c|c|c|c|}
\hline Variable & $\begin{array}{c}\text { RTOG } \\
\text { 0236 } \\
\text { (SBRT) }\end{array}$ & $\begin{array}{l}\text { ACOSOG Z4032 } \\
\text { (sublobar } \\
\text { resection) }\end{array}$ & $\begin{array}{c}\text { ACOSOG } \\
\text { Z4033 } \\
\text { (RFA) }\end{array}$ & $\begin{array}{c}P \\
\text { value* }^{*}\end{array}$ \\
\hline Patients (n) & 55 & 211 & 51 & \\
\hline $\begin{array}{l}\text { 30-d Overall } \\
\text { mortality }\end{array}$ & 0 & $3(1.4)$ & $1(2.0)$ & 6 \\
\hline $\begin{array}{l}\text { 90-d Overall } \\
\text { mortality }\end{array}$ & 0 & $5(2.4)$ & $2(3.9)$ & .5 \\
\hline $\begin{array}{l}\text { Treatment-related } \\
\text { mortality }\end{array}$ & 0 & 0 & $1(2.0)$ & .07 \\
\hline Grade $3+$ AEs at $30 \mathrm{~d}$ & $5(9.1)$ & $59(28.0)$ & NR & .004 \\
\hline Grade 5 AEs at $30 \mathrm{~d}$ & 0 & $3(1.4)$ & NR & .37 \\
\hline Grade $3+$ AEs at $90 \mathrm{~d}$ & $12(21.8)$ & $70(33.2)$ & $14(27.5)$ & .24 \\
\hline Grade 5 AEs at $90 \mathrm{~d}$ & 0 & $6(2.8)$ & $2(3.9)$ & .38 \\
\hline
\end{tabular}

died of pneumonitis 30 to 90 days after treatment. No patient had died at 90 days in the SBRT study. In the sublobar resection group, 5 patients had died at 90 days after surgery. ${ }^{7}$ Two patients died of a cerebrovascular accident and pulmonary embolus and another died of cardiopulmonary arrest within 30 days. Three additional deaths had occurred at 30 to 90 days: 1 patient died of cancer progression, 1 was a cardiacrelated death, and 1 patient died of sepsis. ${ }^{7}$ The grade 5 AEs for sublobar resection included 1 prolonged air leak, 1 stroke, 1 aspiration event, 1 cardiac-related event, 1

TABLE 4. Strata 1-5 created for propensity-matched comparison of RTOG 0236 and ACOSOG Z4032 in patients with stage IA NSCLC

\begin{tabular}{lccc}
\hline \multicolumn{1}{c}{ Strata 1-5 } & RTOG 0236 & ACOSOG Z4032 & $\boldsymbol{P}$ value \\
\hline Strata 1 & & & \\
Patients (n) & 4 & 42 & \\
Median age (y) & 66 & 70 & .57 \\
ECOG 1-2 (n) & $2(50)$ & $36(86)$ & .14 \\
DLCO (\%) & 28 & 30 & .4 \\
FEV (\%) & 25 & 39 & .016 \\
90-d Grade 3+ AEs & $1(25)$ & $20(48)$ & 1.0 \\
Strata 5 & & & \\
Patients (n) & 13 & 34 & \\
Median age (y) & 74 & 73 & .5 \\
ECOG 1-2 & $9(70)$ & $24(71)$ & 1.0 \\
DLCO & 83 & 69 & .03 \\
FEV & 79 & 56 & .036 \\
90-d Grade 3+ AEs & $3(23)$ & $8(24)$ & 1.05 \\
\hline
\end{tabular}

Data in parentheses are percentages. Strata 2-4 will be included in an Appendix. RTOG, Radiation Therapy Oncology Group; ACOSOG, American College of Surgeons Oncology Group; ECOG, Eastern Cooperative Oncology Group; DLCO, carbon monoxide diffusing capacity of the lung; $F E V_{l}$, forced expiratory volume in 1 second; $A E s$, adverse events; $N S C L C$, non-small cell lung cancer. 
nonspecific infection, and 1 pneumonia. The grade $5 \mathrm{AEs}$ for RFA included 1 pneumonitis and 1 sudden death. Complications related to pretreatment biopsy such as pneumothorax were not included as AEs for any of the studies.

A propensity analysis was performed to compare SBRT and sublobar resection in patients with $\mathrm{T} 1$ lesions, similar to the planned comparison in the new, ongoing randomized trial comparing SBRT and surgery (ACOSOG Z4099/RTOG 1021). There were 208 sublobar resection patients with $T 1$ lesions, of whom 202 had baseline PFT data available for the propensity-based analysis. There were 44 SBRT patients with $\mathrm{T} 1$ lesions, of whom 32 had baseline PFT data available for the propensity-based analysis. The primary endpoints included the 30-day and 90-day 3+ AEs. Age, Eastern Cooperative Oncology Group performance score, preoperative $\mathrm{FEV}_{1} \%$, and $\mathrm{DLCO} \%$ were used to build a propensity score. From the propensity analysis, no difference was seen in the 30-day (odds ratio, 2.37; 95\% confidence interval, $0.75-9.90 ; P=.18$ ) or 90 -day (odds ratio, $1.92 ; 95 \%$ confidence interval, 0.71-6.08; $P=.25$ ) grade $3+$ AEs. The patients were classified into 5 groups: 32 from the SBRT study and 202 from the sublobar resection study. Within stratum 1 for sublobar resection $(n=42)$, the median age was 70 years, the median DLCO $\%$ was $30 \%$, and the median $\mathrm{FEV}_{1} \%$ was $39 \%$. In this stratum, the 90 -day grade $3+\mathrm{AE}$ rate was $48 \%$, with a 90 -day mortality of $2.4 \%$. In contrast, within strata 5 for sublobar resection $(n=34)$, median age was 73 years, DLCO $\%$ was $69 \%$ and $\mathrm{FEV}_{1} \%$ was $56 \%$. Within this stratum, the 90 -day grade $3+\mathrm{AE}$ rate was $24 \%$, with no mortality at 90 days (Table 4 ).

An additional analysis was performed examining pulmonary function before and after treatment between the SBRT and sublobar resection groups for $\mathrm{DLCO} \%$ and $\mathrm{FEV}_{1} \%$ using repeated measures analysis of variance with the strata as a repeated factor and the baseline PFT as a covariate. Posttreatment values were collected 90 days after surgery or SBRT completion. Figure 1 outlines the pre- and posttreatment $\mathrm{DLCO} \%$ and $\mathrm{FEV}_{1} \%$ for these studies. No difference was seen in the change in DLCO $\%$ in patients treated with SBRT versus surgery $(P=.92)$. For the sublobar resection patients, after adjustment, the $\mathrm{FEV}_{1} \%$ was $6.4 \%$ greater than that in the SBRT subjects at follow-up, after adjusting for the baseline $\mathrm{FEV}_{1} \%(P=.024)$.

\section{DISCUSSION}

Although the standard of care for treatment of early-stage NSCLC in low- to moderate-risk patients remains lobectomy with systematic lymph node assessment, the classification and treatment selection of the inoperable or high-risk population is more challenging. Historically, the treatment options were less efficacious for medically inoperable patients until the advent or application of SBRT for early NSCLC. Conventional external beam radiotherapy was associated with poor survival and significant morbidity. ${ }^{24-29}$ For the high-risk
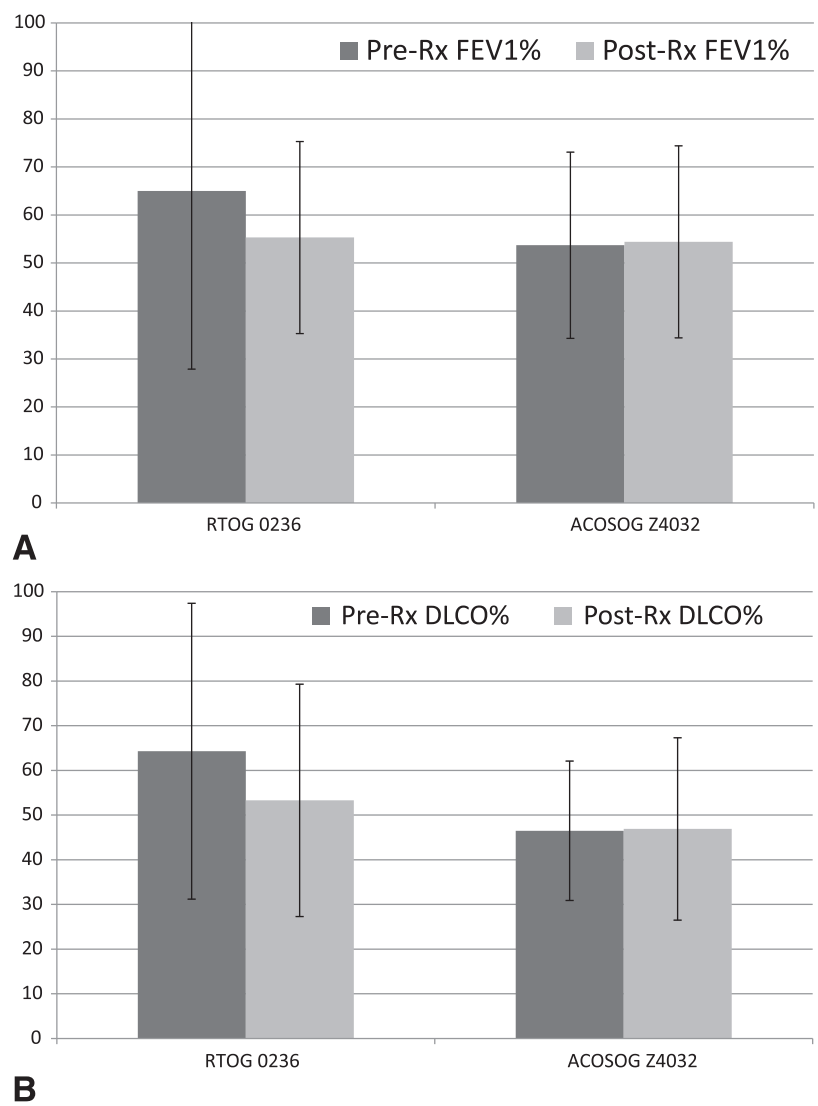

FIGURE 1. A, Pretreatment and post-treatment (90-day) comparison of percentage of predicted forced expiratory volume in 1 second $\left(F E V_{l} \%\right)$ between Z4032 and Radiation Therapy Oncology Group (RTOG) 0236. For patients in $\mathrm{Z} 4032, \mathrm{FEV}_{1} \%$ was $6.4 \%$ greater than that in the RTOG 0236 subjects at follow-up after adjusting for baseline $\mathrm{FEV}_{1} \%(P=.024)$. B, Pretreatment and post-treatment (90-day) comparison of percentage of predicted carbon monoxide diffusing capacity of the lung $(D L C O \%)$ between $\mathrm{Z} 4032$ and Radiation Therapy Oncology Group (RTOG) 0236. No difference were seen in the change in DLCO\% in patients treated with stereotactic body radiotherapy (SBRT) and those treated with surgery in Z4032 $(P=.92)$. ACOSOG, American College of Surgeons Oncology Group.

surgical population, sublobar resection offered the only viable treatment option in these patients, but significant risk was often incurred. The evaluation of these data have shown no short-term mortality for SBRT, with 90-day overall mortality of $2.4 \%$ and $2 \%$ for surgery and RFA, respectively. Contemporary perioperative mortality for lobectomy is $0.8 \%$ to $2.0 \%$ in a low- to moderate-risk group of patients. ${ }^{30-32}$ Many experienced thoracic surgeons now favor minimally invasive or video-assisted thoracic surgery approach because of the associated decrease in morbidity and length of stay compared with standard thoracotomy, which was the approach for most patients in ACOSOG Z4032. ${ }^{32-35}$ The treatment-related mortality rate of $2.0 \%$ for RFA in the ACOSOG Z4033 trial is consistent with that from other small series with procedure-related mortality of $1.5 \%$ to $2.6 \% .^{36,37}$ The pending results from ACOSOG Z4033 should help to 
address the procedure-related morbidity and mortality from RFA and help define the role of RFA in this setting.

Regarding treatment-related morbidity, in an unmatched comparison, 90-day AEs were more common with surgery than with SBRT. In a matched comparison using regression analysis and propensity matching, no difference was seen in 30- and 90-day AE rates between the treatment modalities. Several factors should be considered in this comparison of outcomes. Most surgical complications are acute or subacute, occurring within the first 30 to 90 days. Some complications of SBRT, such as pain, rib fracture, radiation pneumonitis, or a decline in pulmonary function, can occur several months or years after treatment and were not accounted for with this short-term analysis. For all these trials, the lesions were selected because of their peripheral location, excluding stage I tumors that were deeper within the parenchyma. Treatment of more central lesions with surgery, SBRT, and RFA is associated with greater procedure-related morbidity compared with the peripheral lesions. ${ }^{12,37-39}$ From a surgical perspective, these more central lesions would likely require more complex sublobar resection or lobectomy with the associated loss of more functional lung parenchyma and thus a potential increase in morbidity. Most importantly, these short-term data should ultimately be compared within the context of the relative efficacy of the treatment modality on overall and disease-free survival after longer follow-up.

Although some objective criteria are available that can help define the high-risk or inoperable group of patients, these criteria are often debated, and, in many cases, this assessment is subjective. Examination of the available PFT data for the inoperable patient undergoing SBRT in RTOG 0236 would suggest that many of these patients could have been considered surgical candidates, albeit, high risk, and could have been offered surgery or SBRT. Given the mean preoperative $\mathrm{FEV}_{1} \%$ of $65 \%$ and DLCO $\%$ of $64 \%$ in the RTOG 0236 stage T1 patients, the perception of most experienced thoracic surgeons according to the data presented would be to recommend surgical resection and, possibly, lobectomy in the absence of other obvious comorbidities. It is much more complicated than this, because pulmonary insufficiency might not account for all patients deemed medically inoperable in the SBRT-treated group. ${ }^{40}$ In previous retrospective studies of SBRT, treatmentrelated morbidity was inversely related to $\mathrm{FEV}_{1}$ and DLCO. ${ }^{40}$ The implication is that patients with good pulmonary function are often poor surgical candidates because of other nonpulmonary comorbidities. These nonpulmonaryrelated comorbid factors such as heart disease might be poor prognostic indicators in this population. Thus, the subjective classification of inoperability by a surgeon or pulmonologist does not allow for an objective assessment of operability and for comprehensive comparisons between studies. The factors identified in multivariate models as the predictors of morbidity and mortality for lung cancer surgery include $\mathrm{FEV}_{1}$, DLCO, performance status (Zubrod and Eastern Cooperative Oncology Group scales), American Society of Anesthesiology ratings, renal dysfunction, steroid use, body mass index, age, diabetes, male gender, and dyspnea scores (Medical Research Council classification). ${ }^{41-44}$ These parameters should be documented in any trial of high-risk or inoperable patients. Furthermore, we should establish a risk stratification score using these parameters to define the predictive mortality and morbidity for patients to guide trial development and treatment selection in lieu of evolving nonsurgical therapies for high-risk patients with early-stage NSCLC.

Some critics of ACOSOG Z4032 have suggested that the entrance criteria are too broad, allowing for inclusion of healthier, nonhigh-risk patients. There does appear, however, to be a subset of high-risk patients with incrementally greater surgical morbidity relative to other patients in the trial. The 90-day $\mathrm{AE}$ rate doubled from quintile 1 $\left(\mathrm{FEV}_{1} \%, 56 \%\right.$; DLCO $\%, 69 \%$; 90-day 3+ AE rate, $24 \%)$ to quintile $5\left(\mathrm{FEV}_{1} \%, 39 \%\right.$; DLCO $\%, 30 \%$; 90 day $3+\mathrm{AE}$ rate, $48 \%$ ). These data do not suggest that we should abandon the use of sublobar resection in high-risk patients. It would, however, suggest that there might be equipoise between SBRT and surgery to support the necessary inclusion into a randomized trial. Other retrospective, propensity-matched, comparative studies of SBRT and surgery have suggested a relatively high morbidity and mortality rate in the surgical cohort. In the surgery cohorts matched to the high-risk or inoperable patients undergoing SBRT, the procedure-related mortality was $7 \%$ to $8.3 \%$ compared with $0 \%$ to $1.7 \%$ for the SBRT cohort. ${ }^{18,45,46}$ These data would again suggest that there is a subset of high-risk patients offered surgery who might have prohibitively high morbidity and mortality, creating an opportunity to examine alternative less-invasive therapies.

There are other factors to consider regarding the role of SBRT versus surgery in this population. In ACOSOG Z4032, 29.3\% of clinical stage I patients were ultimately staged at a greater pathologic stage at surgery. In other reports of patients with clinical stage I NSCLC, 35\% were ultimately found to have a greater pathologic stage at surgery, with $13.8 \%$ having occult stage N1 disease and $3.5 \%$ occult $\mathrm{N} 2$ disease. ${ }^{18}$ Subsequent chemotherapy was given to $21 \%$ of patients upstaged with surgery, but none of the SBRT patients received adjuvant therapy. ${ }^{46}$ Nonetheless, nodal failure was only encountered in 2 of 55 patients in the RTOG $0236 .{ }^{22}$ Multiple factors have been proposed to explain this discrepancy between nodal detection in the surgical series and a relative lack of nodal failure with SBRT, including the inadequacy of detecting clinical nodal failure and the peripheral radiation dose. The proportion of patients with nodal upstaging was lower in Z4032 (1.4\% stage $\mathrm{N} 1$ and $1.4 \%$ stage $\mathrm{N} 2)$ compared 
with other reports, and this might have been related to a reticent approach to nodal dissection in this high-risk group undergoing sublobar resection. In the ACOSOG Z4032, $12.8 \%$ of patients had no documented nodal assessment at surgery. Failure to systematically assess for nodal disease at surgery, even within the context of a sublobar resection in high-risk patients, negates the benefit of surgical identification of occult nodal disease and precludes the use of adjuvant therapy. These data reiterate the inadequacy of clinical staging with positron emission tomography/CT and suggest that a poorly executed sublobar resection with inadequate assessment of margins and without systematic nodal dissection might not provide superior outcomes compared with alternative tumor ablation technologies.

Although the data are limited, the relative preservation of pulmonary function in the surgically treated group compared with the SBRT patients is perhaps an unanticipated finding for some. The proponents of SBRT often cite the preservation of lung function as an advantage over surgery. Surgical series, however, have shown good preservation of pulmonary function after sublobar resection. ${ }^{3,4}$ Additionally, the lung volume reduction achieved by resection in those with localized emphysema might contribute to this finding. The present study was inherently limited by the retrospective comparison of these cohorts in small, presumably different, populations. Additional exclusion of SBRT patients because of incomplete pulmonary function data might also have obscured the comparative results, given the small sample size. It is likely that patients deemed inoperable because of nonpulmonary comorbidities were less likely to undergo PFTs. This might have excluded a more ill subset of SBRT patients for the comparison because nonpulmonary, cardiac-related morbidity might portend a worse outcome in this population. Many of these issues will be addressed in the ongoing cooperative group study, ACOSOG Z4099/RTOG 1021. This phase III randomized multi-institutional trial examines the role of sublobar resection versus SBRT in the treatment of high-risk patients with stage I NSCLC. The primary objective is the 3-year overall survival, and secondary objectives include locoregional recurrence, disease-free survival, AEs, PFTs, and cost and quality of life comparisons. These trial results will be crucial in helping us identify the relative efficacy of these treatments in the high-risk population and repudiate or affirm current assumptions made about the relative role of each treatment modality.

I would like to thank Donna Vernaci and Jennifer Bell for their assistance with formatting and preparation of this study.

\section{References}

1. Mery CM, Pappas AN, Bueno R, Colson YL, Linden P, Sugarbaker DJ, et al. Similar long-term survival of elderly patients with non-small cell lung cancer treated with lobectomy or wedge resection within the Surveillance, Epidemiology, and End Results database. Chest. 2005;128:237-45.
2. Raz DJ, Zell JA, Ou SH, Gandara DR, Anton-Culver H, Jablons DM. Natural history of stage I non-small cell lung cancer: implications for early detection. Chest. 2007;132:193-9.

3. Harada H, Okada M, Sakamoto T, Matsuoka H, Tsubota N. Functional advantage after radical segmentectomy versus lobectomy for lung cancer. Ann Thorac Surg. 2005;80:2041-5.

4. Keenan RJ, Landreneau RJ, Maley RH Jr, Singh D, Macherey R, Bartley S, et al. Segmental resection spares pulmonary function in patients with stage I lung cancer. Ann Thorac Surg. 2004; 78:228-33.

5. Odell DD, Kent MS, Fernando HC. Sublobar resection with brachytherapy mesh for stage I non-small cell lung cancer. Semin Thorac Cardiovasc Surg. 2010;22:32-7.

6. Santos R, Colonias A, Parda D, Triombetta M, Maley RH, Macherey R, et al. Comparison between sublobar resection and ${ }^{125}$ iodine brachytherapy after sublobar resection in high-risk patients with stage I non-small-cell lung cancer. Surgery. 2003; 134:691-7.

7. Fernando HC, Landreneau RJ, Mandrekar SJ, Hillman SL, Nichols FC, Meyers B, et al. Thirty- and ninety-day outcomes after sublobar resection with and without brachytherapy for non-small cell lung cancer: results from a multicenter phase III study. J Thorac Cardiovascular Surg. 2011;142:1143-51.

8. Pennathur A, Luketich JD, Abbas G, Chen M, Fernando HC, Gooding WE, et al. Radiofrequency ablation for the treatment of stage I non-small cell lung cancer in high-risk patients. J Thorac Cardiovascular Surg. 2007;134:857-64.

9. Lencioni R, Crocetti L, Cioni R, Suh R, Glenn D, Regge D, et al. Response to radiofrequency ablation of pulmonary tumours: a prospective, intention-to-treat, multicentre clinical trial (the RAPTURE study). Lancet Oncol. 2008;9:621-8.

10. Lanuti M, Sharma A, Digumarthy SR, Wright CD, Donahue DM, Wain JC, et al. Radiofrequency ablation for treatment of medically inoperable stage I non-small cell lung cancer. J Thorac Cardiovascular Surg. 2009;137:160-6.

11. Dupuy DE, DiPetrillo T, Gandhi S, Ready N, Ng T, Donat W, et al. Radiofrequency ablation followed by conventional radiotherapy for medically inoperable stage I non-small cell lung cancer. Chest. 2006;129:738-45.

12. Timmerman R, McGarry R, Yiannoutsos C, Papiez L, Tudor K, DeLuca J, et al. Excessive toxicity when treating central tumors in a phase II study of stereotactic body radiation therapy for medically inoperable early-stage lung cancer. $J$ Clin Oncol. 2006;24:4833-9.

13. Lagerwaard FJ, Haasbeek CJ, Smit EF, Slotman BJ, Senan S. Outcomes of riskadapted fractionated stereotactic radiotherapy for stage I non-small-cell lung cancer. Int J Radiat Oncol Biol Phys. 2008;70:685-92.

14. Nyman J, Johansson KA, Hulten U. Stereotactic hypofractionated radiotherapy for stage I non-small cell lung cancer-mature results for medically inoperable patients. Lung Cancer. 2006;51:97-103.

15. Baumann P, Nyman J, Hoyer M, Gagliardi G, Lax I, Wennberg B, et al. Stereotactic body radiotherapy for medically inoperable patients with stage I non-small cell lung cancer-a first report of toxicity related to COPD/CVD in a nonrandomized prospective phase II study. Radiother Oncol. 2008;88:359-67.

16. Ricardi U, Filippi AR, Guarneri A, Giglioli FR, Ciammella P, Franco P, et al. Stereotactic body radiation therapy for early stage non-small cell lung cancer: results of a prospective trial. Lung Cancer. 2010;68:72-7.

17. Andratschke N, Zimmermann F, Boehm E, Schill S, Schoenknecht C, Thamm R, et al. Stereotactic radiotherapy of histologically proven inoperable stage I nonsmall cell lung cancer: patterns of failure. Radiother Oncol. 2011;101:245-9.

18. Crabtree TD, Denlinger CE, Meyers BF, El Naqa I, Zoole J, Krupnick AS, et al. Stereotactic body radiation therapy versus surgical resection for stage I non-small cell lung cancer. J Thorac Cardiovascular Surg. 2010;140:377-86.

19. Onishi H, Araki T, Shirato H, Nagata Y, Hiraoka M, Gomi K, et al. Stereotactic hypofractionated high-dose irradiation for stage I nonsmall cell lung carcinoma: clinical outcomes in 245 subjects in a Japanese multiinstitutional study. Cancer. 2004;101:1623-31.

20. Palma D, Visser O, Lagerwaard FJ, Belderbos J, Slotman B, Senan S. Treatment of stage I NSCLC in elderly patients: a population-based matched-pair comparison of stereotactic radiotherapy versus surgery. Radiother Oncol. 2011;101: 240-4.

21. Uematsu M, Shioda A, Suda A, Fukui T, Ozeki Y, Hama Y, et al. Computed tomography-guided frameless stereotactic radiotherapy for stage I non-small cell lung cancer: a 5-year experience. Int J Radiat Oncol Biol Phys. 2001;51:666-70.

22. Timmerman R, Paulus R, Galvin J, Michalski J, Straube W, Bradley J, et al. Stereotactic body radiation therapy for inoperable early stage lung cancer. JAMA. 2010;303:1070-6.

23. Common Terminology for Adverse Events, version 3.0. Washington, DC: US Department of Health and Human Services, National Institutes of Health, National Cancer Institute; 2003. 
24. Qiao X, Tullgren O, Lax I, Sirzen F, Lewensohn R. The role of radiotherapy in treatment of stage I non-small cell lung cancer. Lung Cancer. 2003;41:1-11.

25. McGarry RC, Song G, des Rosiers P, Timmerman R. Observation-only management of early stage, medically inoperable lung cancer: poor outcome. Chest. 2002;121:1155-8

26. Fernandez FG, Crabtree TD, Liu J, Meyers B. Sublobar resection versus definitive radiation in patients with stage IA non small cell lung cancer. J Thoracic Cardiovasc Surg. 2012;94:354-61.

27. Bradley JD, Wahab S, Lockett MA, Perez CA, Purdy JA. Elective nodal failures are uncommon in medically inoperable patients with stage I non-small-cell lung carcinoma treated with limited radiotherapy fields. Int J Radiat Oncol Biol Phys. 2003;56:342-7.

28. Slotman BJ, Antonisse IE, Njo KH. Limited field irradiation in early stage (T1-2N0) non-small cell lung cancer. Radiother Oncol. 1996;41:41-4.

29. Sibley GS, Jamieson TA, Marks LB, Anscher MS, Prosnitz LR. Radiotherapy alone for medically inoperable stage I non-small-cell lung cancer: the Duke experience. Int J Radiat Oncol Biol Phys. 1998;40:149-54.

30. Allen MS, Darling GE, Pechet TT, Mitchell JD, Herndon JE II, Landreneau RJ, et al. Morbidity and mortality of major pulmonary resections in patients with early-stage lung cancer: initial results of the randomized, prospective ACOSOG Z0030 trial. Ann Thorac Surg. 2006;81:1013-20.

31. McKenna RJ Jr. New approaches to the minimally invasive treatment of lung cancer. Cancer J. 2005;11:73-6.

32. Paul S, Altorki NK, Sheng S, Lee PC, Harpole DH, Onaitis MW, et al. Thoracoscopic lobectomy is associated with lower morbidity than open lobectomy: a propensity-matched analysis from the STS database. J Thorac Cardiovasc Surg. 2010;139:366-78.

33. Villamizar NR, Darrabie MD, Burfeind WR, Petersen RP, Onaitis MW, Toloza E, et al. Thoracoscopic lobectomy is associated with lower morbidity compared with thoracotomy. J Thorac Cardiovasc Surg. 2009;138:419-25.

34. Petersen RP, Pham D, Burfeind WR, Hanish SI, Toloza EM, Harpole DH Jr, et al. Thoracoscopic lobectomy facilitates the delivery of chemotherapy after resection for lung cancer. Ann Thorac Surg. 2007;83:1245-50.

35. Flores RM, Park BJ, Dycoco J, Aronova A, Hirth Y, Rizk NP, et al. Lobectomy by video-assisted thoracic surgery (VATS) versus thoracotomy for lung cancer. J Thorac Cardiovasc Surg. 2009;138:11-8.

36. Fernando HC, De Hoyos A, Landreneau RJ, Gilbert S, Goodwing WE, Buenaventura PO, et al. Radiofrequency ablation for the treatment of non-small cell lung cancer in marginal surgical candidates. J Thorac Cardiovasc Surg. 2005;129:639-44

37. Simon CJ, Dupuy DE, DiPetrillo TA, Safran HP, Grieco CA, Ng T, et al. Pulmonary radiofrequency ablation: long-term safety and efficacy in 153 patients Radiology. 2007;243:268-75.

38. de Baere T, Palussiere J, Auperin A, Hakime A, Abdel-Rehim M, Kind M, et al. Midterm local efficacy and survival after radiofrequency ablation of lung tumors with minimum follow-up of 1 year: prospective evaluation. Radiology. 2006;240:587-96.

39. Fakiris AJ, McGarry RC, Yiannoutsos CT, Papiez L, Williams M, Henderson MA, et al. Stereotactic body radiation therapy for early-stage nonsmall-cell lung carcinoma: four-year results of a prospective phase II study. Int J Radiat Oncol Biol Phys. 2009;75:677-82.

40. Henderson M, McGarry R, Yiannoutsos C, Fakiris A, Hoopes D, Williams M, et al. Baseline pulmonary function as a predictor for survival and decline in pulmonary function over time in patients undergoing stereotactic body radiotherapy for the treatment of stage I non-small-cell lung cancer. Int J Radiat Oncol Biol Phys. 2008;72:404-9.

41. Buccheri G, Ferrigno D, Tamburini M. Karnofsky and ECOG performance status scoring in lung cancer: a prospective, longitudinal study of 536 patients from a single institution. Eur J Cancer. 1996;32A:1135-41.

42. Berrisford R, Brunelli A, Rocco G, Treasure T, Utley M. The European Thoracic Surgery database project: modelling the risk of in-hospital death following lung resection. Eur J Cardiothorac Surg. 2005;28:306-11.

43. Kozower BD, Sheng S, O’Brien SM, Liptay MJ, Lau CL, Jones DR, et al. STS database risk models: predictors of mortality and major morbidity for lung cancer resection. Ann Thorac Surg. 2010;90:875-83.

44. Wright CD, Gaissert HA, Grab JD, O'Brien SM, Peterson ED, Allen MS. Predictors of prolonged length of stay after lobectomy for lung cancer: a Society of Thoracic Surgeons General Thoracic Surgery database risk-adjustment model. Ann Thorac Surg. 2008;85:1857-65.

45. Palma D, Visser O, Lagerwaard FJ, Belderbos J, Slotman BJ, Senan S. Impact of introducing stereotactic lung radiotherapy for elderly patients with stage I nonsmall-cell lung cancer: a population-based time-trend analysis. J Clin Oncol. 2010;28:5153-9.

46. Robinson CG, El Naqa I, Crabtree T, Meyers B, Puri V, Zoole J, et al. Outcomes after stereotactic body radiation therapy (SBRT) or anatomic surgical resection (ASR) for clinical stage I non-small cell lung cancer. Int J Radiat Oncol Biol Phys. 2010;78:S15.

\title{
COMMENTARY
}

\section{The best that surgery has to offer}

\author{
Thomas A. D'Amico, MD
}

The treatment of patients with stage I lung cancer continues to be examined through decades of controversy:

From the Division of Thoracic Surgery, Department of Surgery, Duke University Medical Center, Durham, NC.

Disclosures: The author has nothing to disclose with regard to commercial support. Received for publication Nov 9, 2012; accepted for publication Dec 5, 2012; available ahead of print Jan 10, 2013.

Address for reprints: Thomas A. D'Amico, MD, Section of General Thoracic Surgery, Duke University Medical Center Box 3496, Duke South, White Zone, Room 3589,

Durham, NC 27710 (E-mail: damic001@mc.duke.edu).

J Thorac Cardiovasc Surg 2013;145:699-701

$0022-5223 / \$ 36.00$

Copyright (C) 2013 by The American Association for Thoracic Surgery

http://dx.doi.org/10.1016/j.jtcvs.2012.12.020 lobectomy versus sublobar resection, minimally invasive strategies versus open approaches, and most recently the use of nonsurgical interventions versus resection. Each of these debates pivots on the competing principles of optimizing oncologic efficacy while minimizing invasiveness and complications. Although the Lung Cancer Study Group established lobectomy as the standard of care for clinical stage I lung cancer, ${ }^{1}$ those findings are being challenged by trials demonstrating equivalent results with segmentectomy in selected patients ${ }^{2}$ and currently being tested again in a prospective, randomized trial (Cancer and Leukemia Group B 140503). ${ }^{3}$ More clearly established is the 